\title{
USO PUBLICO DE LOS ESPACIOS PROTEGIDOS EN LA PROVINCIA DE HUELVA: PRESENTE Y FUTURO
}

Juan Carlos RUBIO GARCIA*

\section{INTRODUCCION}

Todas las nuevas formas de turismo están en mayor o menor medida relacionadas con el medio natural y con la necesidad de su conservación, en respuesta a un uso turístico de la naturaleza que no ha sido respetuoso con ésta, repercutiendo a largo plazo sobre el propio interés del recurso fuente de ingresos.

El progresivo deterioro del medio y el relevante papel económico del sector turístico en sociedades como la nuestra, han generado un gran interés en el desarrollo de encuentros sobre estos temas en todo el mundo, no siendo ajeno a ello nuestro país, en donde recientemente se han celebrado en la Costa Brava (Septiembre 86) unas Jornadas Técnicas sobre Turismo y Medio Ambiente y se han programado las actuales.

El Turismo ha dejado de improvisarse y, hoy día, se cuenta con verdaderos especialistas en su gestión, que está basada en conocimientos técnicos y científicos procedentes de disciplinas muy variadas (economía, geografía, ecología, etc.).

El desarrollo de programas turísticos se fundamenta en trabajos serios de investigación (MARCHENA, 1986), que posibilitan la planificación e implementación de los mismos, estando cada vez más estrechamente relacionados turismo, ordenación del territorio y conservación de la naturaleza.

Uno de los aspectos más relevantes de la política de conservación actual se centra en la existencia de todos los países de una Red de Espacios Protegidos, cuyo objetivo último es el de legar a las generaciones venideras muestras representativas de los ecosistemas con características primigenias.

(*) Dr. en Biología, Director-Conservador del Parque Natural de las Marismas del Odiel. 
Pero, sin embargo, la existencia de unas islas conservadas en el interior de un territorio transformado y deteriorado por las diversas actividades humanas, no garantiza ese fin último, por lo que se tiende en la actualidad a un uso racional del territorio que articule la explotación de los recursos con la conservación de los mismos y, el turismo, no escapa a esta dialéctica.

Por otro lado, el deterioro progresivo del medio ha generado en los últimos años una gran avidez por el contacto directo con la naturaleza conservada. Este fenómeno sociológico ha generado de una parte la preocupación de los gestores de la conservación (RICHEZ, 1986) y, de otra, el interés del sector turístico que contempla este campo como de gran rentabilidad a corto y medio plazo.

La posibilidad de coexistencia y potenciación recíproca de ambos sectores (conservación y turismos) inspira la presente ponencia, que reclama para la provincia de Huelva la puesta en práctica de un programa piloto de desarrollo turístico basado en la conservación de sus ecosistemas.

\section{EL TURISMO COMO PROBLEMA}

El turismo actual es un fenómeno que no tiene más de 50 años, pero que alcanza una gran importancia en países cuyas condiciones naturales han atraído a las corrientes turísticas.

La revolución industrial y la revolución tecnológica a la que asistimos en la actualidad ha conformado una sociedad en la que uno de los principales problemas es el de la "ocupación del tiempo del ocio".

Sin embargo, el tipo de sociedad ha generado grandes conurbaciones que impiden que ese ocio se disfrute en el entorno habitual, buscándose zonas alternativas de esparcimiento donde ocupar el tiempo libre como playas, montaña y, en general, la naturaleza.

Pero esa misma estructura social y productiva ha generado un deterioro irreversible del medio ambiente en amplias zonas, surgiendo la necesidad de desplazarse a otros puntos para el encuentro con zonas naturales atractivas.

Por otro lado, el desarrollo de una oferta turística atractiva y al mismo tiempo rentable ha exigido, con los modelos puestos en práctica hasta la fecha, nuevas concentraciones humanas con gran número de plazas turísticas, desarrollo de infraestructuras adecuadas para poner las zonas turísticas al alcance de la mano, equipamientos en los puntos de acogida de gran sofisticación, traslado de las condiciones de vida habituales y sus comodidades a las zonas turísticas, etc.

Todo ello ha generado transformaciones en las primitivas áreas que supusieron el atractivo inicial, de tal forma que en poco tiempo sufren grandes e irreversibles perturbaciones (GARCIA NOVO, 1981). 
La solución a esta problemática pareció encontrarse en el llamado "turismo verde", que ofrecía una salida airosa para, conservando el territorio a ultranza, se pudiera sacar una rentabilidad de la que tan necesitadas estaban amplias zonas que, por su carácter deprimido, presentaban unas condiciones naturales atractivas, como el caso de Huelva.

Sin embargo, dicha concepción del turismo no ha encontrado respuesta en el sector empresarial que se mueve de forma clara por grandes inversiones de rentabilidad asegurada y sustanciosa, quedando a expensas de la Administración la implementación de estos proyectos, con su consiguiente ralentización y, en muchos casos, paralización por falta de apoyo de la iniciativa privada.

Así, en el caso de Huelva, el desarrollo turístico desde el punto de vista empresarial pasa exclusivamente por lo "costero" (BARRANCO, 1987), siendo necesario para la obtención de rentabilidad la no limitación del número de plazas turísticas ni de tipos de urbanización, manteniendo un respeto al medio, que no suponga una limitación al desarrollo turístico, utilizando el "turismo verde" como simple complemento al desarrollo del resto de infraestructuras de acogida.

\section{PASADO Y PRESENTE DEL TURISMO EN HUELVA}

La evolución del turismo onubense se puede describir, siguiendo a OJEDA (1986), como sigue:

En 1959 se produce en España la liberalización de la entrada de capital extranjero, abriéndose el mercado español a las multinacionales, lo que facilita de forma decisiva el boom turístico que se produce en nuestro país en la siguiente década, convirtiéndolo en el país turístico por antonomasia del continente europeo.

Así, se pasa en tan sólo 12 años de cuatro millones de visitantes a más de treinta, consiguiéndose una entrada de divisas de gran importancia que, junto con la emigración y las inversiones de las multinacionales, contribuyen a la modernización industrial del país y al mantenimiento del equilibrio de la balanza de pagos.

La búsqueda de divisas determina como objetivo básico de atracción al gran turismo internacional, generándose un boom espectacular en la Costa del Sol, que determina su total transformación en el curso de pocos años.

En Huelva, a pesar de las características idóneas que presenta para el turismo balneario, no se produce una respuesta inmediata debido fundamentalmente a su marginalidad respecto de las grandes urbes, manteniéndose inédita en lo referente a la explotación turística de largo alcance.

El proceso turístico que se desarrolla en nuestra provincia es de carácter local y se orienta a la especulación urbanística, que se desarrolla en unos pocos puntos dispersos (La Antilla, Punta Umbría y Matalascañas), proceso que se mantiene hasta nuestros días. 
Este hecho determina que el de Huelva sea el último tramo de costas españolas en buen estado de conservación y con cualidades turísticas óptimas.

En 1961 la Diputación creó la "Comisión de Estudio para la promoción de la Costa" que elaboró el "Avance del Plan de Promoción y Desarrollo de la Costa de Huelva", documento que se plantea la transformación del litoral virgen en una supuesta costa turística internacional, que presenta la explotación de los recursos turísticos como de muy alta rentabilidad, ya que las playas tenían todos los requisitos exigidos por los operadores turísticos:

- Sol, playas y clima favorable.

- Estado salvaje y equilibrio ecológico.

- Ausencias de complejos y puertos industriales, así como de autopistas, redes de ferrocarriles, etc.

Asimismo, su situación determinaba la existencia de un mercado potencial local, nacional e internacional de gran importancia.

Se pensaba que con una adecuada promoción y la retirada de algunos obstáculos (titularidad de los terrenos, infraestructuras, comunicaciones), se podría conseguir desarrollar unos "Centros de Interés Turístico".

Ya entonces se introducían conceptos proteccionistas, propugnándose la conciliación entre la comodidad y confort de los centros residenciales con el paisaje conservado, dejando amplias extensiones costeras sin transformar.

Se especificaba la necesidad de establecer una Sociedad Anónima mixta semipública a través de la Diputación, declarando el turismo como industria de interés nacional para obtener beneficios fiscales y económicos.

La presentación del programa con estas premisas, hacía prever que Huelva aparecería como un centro ideal para las inversiones por los bajos precios de servicios y terrenos y por la existencia de desgravaciones fiscales y créditos públicos.

A raíz de estas iniciativas, la Comisión Interministerial de Turismo elaboró en 1963 el "Proyecto de Promoción Turística de la Costa de Huelva", que propone un plan escalonado de actuaciones por zonas turísticas de interés en cinco etapas (1964-1984).

El diseño del proyecto se basó en la articulación del desarrollo turístico con la industrialización y la conservación del medio litoral.

El proyecto, de carácter grandilocuente, se plasma en algunas actuaciones fallidas como el "Centro de Interés Turístico Nacional de El Portil" o simplemente no se lleva a cabo en otras zonas, dejando que playas como Punta Umbría, Matalascañas y La Antilla, se desarrollen de forma distinta a la prevista, predominando el turismo nacional, a base fundamentalmente de visitantes del entorno local 
y del desarrollo de segundas residencias con un sector hotelero muy pobre, de escaso interés para los operadores turísticos nacionales e internacionales, destacando únicamente la oferta de campings y, por tanto, de turismo de baja calidad que llevan aparejados éstos.

Sin embargo, este fracaso parcial no hace escarmentar a los planificadores, que mantienen hasta nuestros días grandes proyectos (World Hotel, Punta Canela) contestados por diversos sectores, por suponer grandes transformaciones del medio con perturbaciones irremediables, que hacen evocar otros tiempos.

Frente a todo ello se impone la búsqueda de una salida al sector turístico que amplíe la oferta a toda la provincia no circunscribiéndola a la franja litoral, utilizando aspectos turísticos diversos que vayan desde lo ecológico-naturalístico hasta lo cultural, pasando por lo folklórico, gastronómico, etc. que redunde en una disminución de la estacionalidad del fenómeno turístico.

De esta forma, los objetivos básicos del apoyo público al turísmo deben basarse en cuatro puntos:

- Diversificación territorial de la oferta.

- Búsqueda de nuevos recursos turísticos a explotar.

- Captación de servicios hoteleros.

- Mejoría en infraestructuras y equipamientos.

Ofreciendo en todo momento facilidades crediticias y adminsitrativas; actuando como intermediario en las operaciones; asesorando técnica y comercialmente los proyectos turísticos y proveyendo de suelo clasificado y ordenado para uso turístico.

De esta forma el turismo no debe contemplarse como una actividad más o de carácter marginal dentro de la economía provincial, ya que si alcanza un aceptable nivel de desarrollo, se convertiría en el verdadero motor económico, determinando los niveles de renta alcanzados por la población.

La planificación turística debe estar basada en profundos estudios de ordenación que superen las problemáticas locales y no permitan la improvisación, provisionalidad y oportunismo con que se han actuado en muchas ocasiones, siendo un claro ejemplo de ello la incomprensión generalizada de la administración hacia la problemática del "mosquito", de soluciones tan claras, abordadas en distintas zonas del mundo, de condiciones naturales similares a la nuestra. Otro ejemplo estaría constituido por la dinámica litoral de nuestra costa, cuyo funcionamiento geomorfológico de dinámica muy activa, hace muy delicado y peligroso el lanzarse a multitud de nuevos proyectos, entre los que destacan los puertos deportivos, sin un análisis serio de la realidad y las repercusiones de las intervenciones humanas. 
La potencialidad de crecimiento del turismo onubense debe contribuir en el dinamismo de este sector, mediante el logro de un aprovechamiento integral de sus recursos turísticos, con una adecuada ordenación de la oferta, explorando las posibilidades de sus zonas naturales.

La aceptable conservación de amplias zonas de su territorio y el miedo y rechazo a un modelo de desarrollo salvaje, ya probado en otras zonas, ha hecho pensar a ciertos sectores que la única salida viable para el litoral onubense es la implementación del denominado "Turismo verde" que permitiría la conservación de las características naturales del área.

Este argumento ha sido considerado, sin embargo, como una falacia por parte de los empresarios e inversores desde una perspectiva turística actual en la que prima una visión economicista del modelo turístico, presidida por la rentabilidad.

La solución al problema debe venir de la mano de la planificación y ordenación, articulando las dos concepciones del desarrollo turístico, utilizando el turismo verde y deportivo como "complemento" de un turismo convencional respetuoso con el ambiente, que haga a corto plazo rentables las inversiones.

De esta forma, la enorme riqueza potencial de la provincia desde distintos puntos de vista (natural, deportivo, cinegético, rural, etc.) podrían satisfacer, con una promoción idónea, la cada vez más numerosa demanda de plazas turísticas de estos sectores, fuera de época estival.

\section{USO PUBLICO DE LOS ESPACIOS PROTEGIDOS ONUBENSES}

En la actualidad sólo el Parque Nacional de Doñana y el Paraje Natural de las Marismas del Odiel, dependientes de las Administraciones Central y Autonómica, respectivamente, gozan de una figura legal de protección (Ley 151/1975, de 2 de Mayo).

Ambos espacios soportan por diversos motivos graves carencias en infraestructura de acogida y equipamientos turísticos, que determinan un bajo número de visitantes, por lo que se han logrado los objetivos de conservación en un $50 \%$, ya que se han preservado sus ecosistemas pero, hasta el momento, no se ha llegado a difundir entre los ciudadanos el interés de dicha conservación.

Los datos de visita a los Parques Nacionales en España arrojan una cifra de 3.000.000 de personas en 1984 (LABORATORIO, 1986), de los que acudieron a Doñana exclusivamente 160.000 (BARRANCO, 1987), cifra muy baja si se tiene en cuenta el carácter destacado de este Parque Nacional, considerado como el más relevante de Europa. Esta cifra es debida a la escasez de promoción, infraestructuras y equipamientos ofrecido. El hecho se agrava desde el punto de 
vista turístico, ya que la mayor parte de los visitantes eran escolares del entorno integrados en programas de educación ambiental, que constituye el otro gran apartado junto al turismo del uso público de los espacios protegidos, con un tiempo de permanencia muy baja y escasas pernoctaciones.

El Paraje Natural de las Marismas del Odiel, de reciente declaración (Ley 12/ 1984, de 19 de Octubre), no presenta todavía ninguna infraestructura de acogida ni servicio de visitas, al contrario que Doñana, pese a lo cual ha sido visitado en 1986 por más de 100.000 personas, aunque en su inmensa mayoría, procedentes de Huelva capital y con fines recreativos balnearios (playas del espigón).

Los Planes Rectores de Uso y Gestión de ambos espacios (ICONA, 1984; RUBIO, 1986) contemplan los Planes de Uso Público como un capítulo esencial en su desarrollo, relacionando con todo lujo de detalles las necesidades en infraestructuras, equipamientos y personal, así como la programación y promoción del Uso Público.

Sin embargo, este apartado aún no ha alcanzado el suficiente respaldo por los diversos sectores de la administración y, por tanto, de la sociedad, que siguen viendo la existencia de Parques y Parajes como un "lujo útil" (concepto introducido para Doñana por J.F. OJEDA).

El futuro de la conservación de estos espacios pasa ineludiblemente por su difusión y comprensión por los ciudadanos, así como por su rentabilidad directa sobre los habitantes del entorno, siendo el turismo una de las pocas posibilidades de explotación de los mismos, en la que es factible controlar las perturbaciones.

Así, en distintas partes del mundo, se han desarrollado programas turísticos en Parques Nacionales, que se han apoyado en medios transformados a imitación de los ecosistemas del área, situados en cinturones periféricos y con infraestructura y equipamientos turísticos de apoyo, permitiendo a los visitantes de diversa motivación, satisfacer sus distintos intereses evitando en todo momento posibles daños sobre el espacio que se quiere conservar.

Debemos, pues, reflexionar sobre estos aspectos, haciendo ver que el desarrollo de estos programas debe ser una cuestióu común a todos los intereses implicados en los espacios protegidos (organismos, ayuntamientos, empresas particulares) que deben responsabilizarse de su conservación y explotación racional.

\section{EL LITORAL: HACIA LA ORDENACION DE ASENTAMIENTOS TURISTICOS INTEGRADOS}

El turismo en Huelva se ha basado casi exclusivamente en el desarrollo de la franja costera, donde se han llevado a cabo todas las actuaciones en esta materia, con el respaldo de la alta demanda de este sector y las inmejorables condiciones ambientales del litoral. 
El dilema, tantas veces esgrimido, entre desarrollo y conservación, se plantea en el sector turístico en nuestra provincia, en tratar de encontrar un punto de equilibrio entre un adecuado desarrollo de centros turísticos tradicionales, lo más respetuoso que sea posible con su entorno inmediato, siendo rentables en las condiciones económico-sociales de la actualidad y la conservación de amplias zonas, entre dichos centros, que sigan haciendo atractiva el área turística y que sirvan de apoyo a la misma, diseñándose un programa de "turismo verde", como complemento de los núcleos turísticos, obteniéndose una rentabilidad accesoria que justifique la no urbanización de forma continua de toda la costa.

Todo ello pasa por una adecuada ordenación territorial que contemple de forma precisa estas dos perspectivas del problema, delimitando claramente las zonas, mediante un programa de actuación a corto y medio plazo, con una normativa que enlace los instrumentos legales ya existentes (PGOU, PEMF, Planes Litorales, Espacios Protegidos, etc.), con proyectos de desarrollo turístico.

El medio conservado adyacente a los núcleos turísticos debe utilizarse en los programas de marketing publicitario, como punto esencial del atractivo de las áreas, buscándose con ello la presencia de un turismo de calidad media-alta, nacional e internacional, que sepa apreciar el mensaje del área turística y que demande circuitos tradicionales de explotación y otros complementarios de turismo de la naturaleza.

Para ello habría que conseguir una mentalización de los diversos sectores implicados (administración, empresarios, conservacionistas, ecologistas, técnicos, etc.), que tenga como meta el desarrollo equilibrado de las zonas turísticas. De este modo, la imprescindible ordenación trataría de suavizar posturas opuestas, consiguiendo una aceptable rentabilidad, articulación con el entorno y medidas cautelares de protección.

La rentabilidad necesaria, como fin último, en todo proyecto de promoción turística de un área, limitada en cierta medida por la necesidad de ir hacia un "ecodesarrollo", no debe implicar la sobrecarga, a toda costa, de un equipamiento convencional desmedido (atracciones, golf, puertos, deportivos, etc.), cuya ejecución lleva consigo, por lo general, el deterioro de amplias zonas (GARCIA NOVO, 1981; COPEIRO, 1978 y 1982).

La oferta turística debe basarse, por el contrario, en una inmejorble infraestructura de acceso a los diversos núcleos básicos de acogida (abastecimiento, sanidad, residuos, etc.), eliminando problemas tradicionales, como el "mosquito", cuya única solución pasa por el estudio, ordenación, regeneración y conservación de los ecosistemas naturales.

Todo ello, como veremos, debe complementarse con una ampliación de la oferta al resto de la provincia, no circunscribiéndola exclusivamente a la costa, explorando la diversidad y riqueza de sus aspectos culturales, naturalísticos, folklóricos, gastronómicos, etc. 
Así, se conseguirá paliar en gran medida la estacionalidad del turismo actual en Huelva, aprovechando las inmejorables condiciones turísticas de la provincia, desde un punto de vista climatológico, en toda época del año, abriendo el mercado turístico a los distintos sectores de la demanda.

La existencia de una infraestructura básica de acogida, con equipamientos modernos, sin sobrecarga para el medio, y el resto de posibilidades insinuadas, atraería a clases medias y altas en período vacacional, a la tercera edad durante toda época y a grupos de interés específico (congresos, científicos, birdwatchers, etc.) a lo largo del año. Por supuesto, con una oferta bien apoyada en una adecuada campaña de promoción, que cubra el abanico de posibilidades a nivel nacional e internacional, superando el turismo local de segunda residencia, poco rentable económicamente para las zonas turísticas y que tiene colapsado un desarrollo moderno de las mismas.

La atracción de las zonas conservadas, utilizada como bandera de la provincia en un proyecto turístico futuro, no debe quedar estática en los programas de difusión, sino pasar a formar parte de los circuitos turísticos, utilizando de forma racional y ordenada la naturaleza onubense como fuente de ingresos para la provincia. Este camino es, hoy por hoy, la única posibilidad de preservar para el futuro las zonas conservadas de Huelva, fundamentalmente en el litoral.

A pesar de su gran importancia económica, el turismo futuro no debe estar centrado exclusivamente en los viajes organizados de tour-operadores, cuidando especialmente el turismo no vacacional, individualizado, que se interesa por aspectos culturales del país, por su naturaleza, ecología, etc.

La costa onubense, al margen de sus potencialidades actuales, no ha explotado todavía adecuadamente su proximidad con Portugal, y con el flujo de turismo del Algarve, así como un elemento en auge en todo el mundo, el turismo de naturaleza y el especializado deportivo, que no llega a convertirse en un componente esencial de nuestro turismo por falta de infraestructura de acogida y equipamientos idóneos para estas demandas. Destaca fundamentalmente en este "otro turismo" su estacionalidad no convencional, centrada fundamentalmente en primavera y otoño.

Es hora de abordar con decisión la problemática "conservción de la naturaleza-uso turístico de la misma", ya que ambas se justificarían superando el mensaje subliminal o claramente abierto, de una naturaleza singular o salvaje, como motivo de atracción en los programas de promoción turística.

Un seguimiento de lo anterior será fácil de hacer, simplemente con la lectura de la prensa diaria o en folletos y cartelería, como en el caso de Doñana, que aparece en muchas campañas publicitarias turísticas (paradores, touroperadores, etc.) generando normalmente un mensaje equívoco en principio y una desilución posterior. 
El aumento de este turismo comentado se ha dejado notar en otras partes del mundo, así, por ejemplo, una investigación realizada en los estuarios de la costa sur de Australia (CAPUTI y LENANTON, 1977), referente a las actividades recreativas, como punto de atracción para los visitantes, en cuanto a número y pernoctaciones, refleja que la ornitología se ha convertido en una actividad complementaria del turismo, que atrae un porcentaje medio de turistas no despreciable, que alcanza el $7 \%$ en la temporada alta y, lo que es más importante, puede llegar a suponer un $12 \%$ en temporada baja en algunos centros turísticos.

La simple observación de aves en condiciones naturales mueve también a cientos de miles de personas en Europa y el litoral de Huelva posee lugares privilegiados para esta actividad, lo que ha llevado ya a algunas empresas turísticas o al mismo Patronato Provincial, organizador de estas Jornadas, a iniciar proyectos de prueba en este campo.

El litoral presenta un gran interés naturalístico, con un paisaje en mosaico de gran rareza, diversidad y vistosidad, con un conjunto de ecosistemas en los que destaca su riqueza faunística, siendo éste uno de los principales atractivos del área (RUBIO, 1980 y 1985; RUBIO y otros, 1985; FIGUEROA y RUBIO, 1980; GARCIA NOVO, 1980; FERNANDEZ y otros, 1985).

A pesar de que los datos de visitantes, como se ha visto, en este campo en el litoral de Huelva son muy bajos, el "Laboratorio de Planificación Turística" de la Junta de Andalucía, prevé que en tan sólo dos años, creando infraestructuras adecuadas, para una posible red de espacios litorales protegidos, unos 300.000 visitantes con más de 500.000 pernoctaciones, lo que supondría un notable incremento (aún con reducciones en dichas cifras), si tenemos en cuenta que el total de pernoctaciones en 1986 no ha alcanzado la cifra de 700.000 .

Sin embargo, todas estas previsiones son baldías, si no se planifican intervenciones serias de la administración en la dotación de una red de espacios naturales protegidos en la provincia, con infraestructuras y equipamientos adecuados que, aunque suponga una gran inversión a corto plazo, redundaría en sustanciosos beneficios en el futuro.

La principal carencia de esta oferta turística se centra en la ausencia de una infraestructura de uso y disfrute del medio natural, que haga posible el aprovechamiento turístico de las inmejorables condiciones del área que pueda transformar la demanda marginal actual, en una parte importante del sector turístico de Huelva.

Ya que la motivación debe ser favorecer el contacto de los visitantes con el medio natural las formas tradicionales de acceso al recurso turístico deben restringirse a zonas próximas a los espacios a visitar, localizando en ellas las infraestructuras de acogida (restaurantes, bares, comercios, aparcamientos), desde las que, con una adecuada información, poder acceder al medio natural mediante recorridos o senderos señalizados, dotados de infraestructuras "blandas" (observatorios, zonas de descanso, pasarelas, etc.). 
Es incuestionable los presupuestos básicos de conservación que presiden esta ponencia, por lo que se eutiende que la ordenación del territorio provincial en todos sus aspectos debe utilizar este objetivo primordial, siendo respetuosa con los distintos espacios catalogados en el P.E.M.F., que deben constituir los eslabones de la cadena del nuevo turismo que se propone.

Sin embargo, el atractivo de las zonas conservadas a visitar, se perdería en gran parte si carecieran de una estructura administrativa adecuada y una figura de protección - como veremos más adelante existen figuras legales que se adaptan a las distintas zonas de la provincia y que posibilitan conservación y uso turístico- así como de una organización activa, siguiendo las directrices de la "educación ambiental", facilitando la accesibilidad de los espacios protegidos desde dos puntos de vista: físico y cognoscitivo.

El objetivo básico de conservación del patrimonio natural y la potenciación de su aprovechamiento turístico se conseguirá, haciendo de los espacios protegidos un foco de interés y atracción turística, que complementaría en gran medida el turismo convencional en temporada alta y supondría un gran estímulo para el sector fuera de temporada.

El aprovechamiento del territorio en el litoral y la necesidad de infraestructuras no impactantes obligan a la planificación y previsión de medios alternativos a los ya existentes para el disfrute del recurso turístico a explotar, la naturaleza conservada.

Para ello habría que utilizar los tres medios posibles: tierra, agua y aire.

Por tierra junto a los senderos ya mencionados se podrían explorar los recorridos en vehículos todo terreno y los itinerarios a caballo, de corta a larga duración, con logística de apoyo y puntos de parada y alojamiento de carácter turístico, siguiendo algunos de los caminos tradicionales de la provincia (romerías, cañadas reales, cordeles, veredas de carne, etc.) y ya iniciado en Doñana aunque deficitariamente, que se podría extender a Sierra y Andévalo.

Por agua se podría explotar el atractivo de los recorridos fluviales y litorales por marismas y playas, obteniendo una visión del medio inabordable desde tierra firme, con connotaciones lúdicas incuestionables, sirviendo en este aspecto la experiencia realizada recientemente en el Odiel con las "canoas" de Punta Umbría, tradicional transporte de viajeros con Huelva, de temporada, que al tiempo que incrementa el atractivo turístico de la zona, proporciona ingresos complementarios al margen del verano. Este medio es potencialmente muy rico en toda la costa por la infraestructura material y humana ligada a la actividad pesquera que podría diversificarse. 
Por aire, a escasa altura, pueden contemplarse (sobre todo en la costa) paisajes de gran belleza por su diversidad de ambientes (playas, dunas, marismas) pudiéndose explorar la tecnología de los dirigibles (LABORATORIO, T., 86) de escaso impacto ambiental, aunque de desconocida rentabilidad para realizar recorridos de corta duración u obtener perspectivas desde puntos fijos de observación, como sería el caso de la flecha de Nueva Umbría (COPEIRO, 1985).

A pesar de todo lo anterior, no hay que olvidar, que ese proyecto a medio plazo debe sustentarse en otro de mayor inmediatez, que explore el desarrollo urbanístico de determinados puntos de interés, fundamentalmente costeros, que posibiliten una rentabilidad directa y creen focos de atracción para el gran turismo, sin olvidar que para el posterior desarrollo del programa, estos núcleos deben articularse perfectamente con el entorno.

Es necesario crear una nueva oferta de alojamiento hotelero de capacidad y calidad, en la que predominen hoteles, apartahoteles y bungalows, frente a los apartamentos y segundas residencias, con el desarrollo de equipamientos como campos de golf y campos deportivos que sean respetuosos con el entorno, sobre todo estos últimos, por los graves problemas de diversa índole que debían soportar en la costa onubense (COPEIRO, 1978 y 1982), por lo que habría que atender al acondicionamiento de los ya existentes siempre que fuera posible.

Esta oferta de alojamiento debería asentarse en unos cuantos puntos de interés, superando el déficit creado por la no implementación de antiguos proyectos de desarrollo turístico como el "Proyecto de Promoción Turística de la Costa de Huelva" (COMISION INTERMINISTERIAL DE TURISMO, 1963), sin llegar a una sobresaturación ni desarrollismo salvaje, como el caso de los primitivos proyectos de Isla Canela o El Portil como Centro de Interés Turístico Nacional (LAGUNAS DEL PORTIL, S.A., 1973), que supusieron un modelo fracasado de desarrollo turístico conceptuado como "Costa del Sol" (MENANTEAU y MARTIN, 1983).

Se podrían crear unas 30.000 plazas de este tipo, repartidas en siete núcleos, siguiendo la costa de Oeste a Este: Isla Canela, La Antilla, Nueva Umbría, El Portil, Punta Umbría, Asperillo y Matalascañas.

El desarrollo de dichos núcleos se abordaría desde dos perspectivas:

- Ordenar y mejorar con equipamientos e infraestructuras nuevas aquellos núcleos con algún desarrollo, reacondicionándolos al nuevo modelo turístico, como el caso de La Antilla, El Portil, Punta Umbría y Matalascañas.

- Nueva creación, como oportunidad de hacer centros turísticos modelo en el caso de Isla Canela, Nueva Umbría y Asperillo. 
El desarrollo turístico debe estar presidido por la integración de los núcleos en el entorno con la adopción de todo tipo de medidas que impidan su deterioro ( $\mathrm{Sa}$ neamientos, depuradoras, paisajismo, ruidos, etc.) y su imbricación con una red de espacios protegidos, que sirvan como recurso turístico que genere demanda y que, por tanto, sea imprescindible su conservación.

Un ejemplo significativo de esta nueva concepción, se encuentra en el proyecto piloto de "Actuación Urbanística en Nueva Umbría: Estudios de Condicionantes Ambientales" (COPEIRO, 1985), en el que la conservación del medio natural (Flecha del Rompido), considerado de gran riqueza paisajística, geomorfológica y ecológica, se utiliza como justificación del programa del desarrollo turístico, que se adapta en todo momento en su perpetuación, estableciendo medidas de consolidación de dicho medio natural y actuaciones destinadas a integrar el núcleo turístico en el mismo, minimizando los impactos, tras la elección de la ubicación más idonea, después de un estudio ecológico y técnico serio.

En el mencionado trabajo se va más allá y se recomienda la utilización del espacio natural a proteger como fuente directa de atracción turística, promoviendo actividades que contemplan el espacio protegido (con mínimas infraestructuras de acogida), como principal equipamiento del centro turístico a desarrollar, en el que se buscaría un turismo de alto stading, con demanda de zonas inalteradas y contacto con la naturaleza.

En resumen, la filosofía de actuación de este futuro desarrollo turístico, si quiere conservarse el recurso de partida, consistiría en diseñar actuaciones urbanísticas integradas en profundidad con el medio natural, capaces de asimilar lo esencial de éste sin desfigurarlo.

Para no caer en una actuación camuflada, ejemplar en la propaganda política y en la promoción turística, pero vacía de contenido real, se tendrían que articular actuaciones verdaderamente respetuosas con el medio, con proyectos capaces de aprovechar sus características, para elaborar un producto altamente atractivo, de gran calidad comercial.

Las soluciones formales pasarían por una muy cuidada arquitectura paisajista, realizada por verdaderos especialistas, con una organización del espacio a base de grandes zonas abiertas dentro de los núcleos, manejadas hacia lo natural y su adecuación al desarrollo de una red de espacios protegidos que la justificasen.

Otro tanto cabría pensar de la Sierra y el Andévalo, aunque en este caso habría que ir a una integración de la oferta hotelera en los núcleos urbanos más importantes o sus cercanías (Aracena, Aroche, Almonaster, etc.) desarrollando una política de Parques Naturales, que como veremos es la más adecuada para estas zonas agrestes. 


\section{LOS PARQUES NATURALES: MODELO DE ECODESARROLLO PARA LA COMARCA DE LA SIERRA}

Los Parques Naturales son amplias zonas habitadas en donde se hace compatible el desarrollo sostenido de los recursos con la conservación de los valores naturales. Este ecodesarrollo fomenta las actividades tradicionales logrando un mejor aprovechamiento de la potencialidad del medio (AZCARATE, 1986), conservando las singularidades naturales y culturales del espacio a largo plazo, lo que en definitiva favorece la perduración de su rentabilidad.

Esta figura se utiliza en estensas comarcas naturales de carácter especial, que coinciden con regiones económicamente deprimidas (DIAZ DEL OLMO y MOLINA, 1986), tendiéndose con la creación del Parque a coordinar y racionalizar el aprovechamiento y desarrollo de sus múltiples recursos, siendo el turismo uno de los de mayor relevancia.

Los objetivos de un Parque Natural son muy variados, orientándose a la protección (paisaje, ecosistemas, patrimonio, etc.); a la promoción del desarrollo socioeconómico y al disfrute público, mediante el fomento del turismo y de la educación ambiental.

La declaración, por tanto, de un Parque de estas características sienta las bases del desarrollo equilibrado del área escogida, porque esto implica la implementación de los consiguientes Planes de Actuación, que actúan como el motor del desrrollo socioeconómico, que benefician el espacio con las ayudas necesarias, mediante financiaciones de diversa índole.

El uso turístico de los Parques Naturales se convierte, con el desarrollo de los mismos, en una de sus principales actividades (ALMEIDA, 1985; GARAY, 1985; ZAMORA y NICOLAS, 1985), habiendo adquirido los programas de Parques Naturales un gran desarrollo en otros países como Francia (AMA, 1985; F.P.N.F., 1982), donde turismo rural y naturalístico tienen un destacado protagonismo.

Desde este punto de vista, se podría realizar un proyecto de declaración de un gran Parque Natural en las tierras altas de Huelva, que englobe las zonas de Andévalo y Sierra de mayor riqueza natural poniendo en funcionamiento en el mismo un programa de turismo rural en el que el uso turístico de los recursos naturales, ofrezca una imagen diferente a la del turismo tradicional, evitándose la masificación, mediante una oferta turística más selectiva, que repercutirá en la conservación de las áreas naturales y de sus paisajes, proporcionando beneficios socioeconómicos a los habitantes de la zona. 
Con una adecuada planificación, ordenación y promoción de este nuevo tipo de turismo, basadas en la amplia gama paisajística y ecológica y en las ricas tradiciones del área (costumbres, fiestas, romerías, artesanía, arquitectura, gastronomía, etc.), se obtendría una nueva oferta turística de calidad inmejorable.

El sistema de desarrollo propuesto se basa en el aprovechamiento y recuperación de una comarca serrana deprimida, por medio de pequeñas inversiones, con el objeto de articular un mayor disfrute de la zona por sus habitantes, generando asimismo una mejora en los servicios de acogida.

Ello se conseguiría a través de un convencimiento previo de los propios habitantes y de las autoridades locales, acompañado de inversiones sectoriales de todas las administraciones, cuyas consecuencias inmediatas serían un déficit a corto plazo y un discreto número de visitantes, pero que supondría la conservación del recurso turístico a largo plazo, por medio de un desarrollo sostenido que mantenga los niveles de acogida y rentabilidad.

En este sentido, el objeto turístico estaría constituido, no sólo por el paisaje, sino por el hombre que está inmerso en él y sus actividades productivas, culturales y lúdicas. Por tanto, habría una interminable lista de equipamiento turístico espontáneo que requeriría una inversión no demasiado costosa para su utilización.

Así, se podrían obtener las siguientes proyecciones del espacio:

- Ecología: Flora, Fauna, Paisajes, Espacios Protegidos, Itinerarios Ecológicos, etc.

- Deportes y Salud: Caza, Pesca, Senderismo, Deportes al Aire libre, etc.

- Geografía: Sierra, Andévalo, etc.

- Cultura: Museos, Artesanías, Romerías, Toros, Semana Santa, Fiestas populares, etc.

- Gastronomía: Cocina, Vinos, Repostería.

- Rutas: Geológicas, Ecológicas, Arqueológicas, Artísticas, Históricas, etc.

- Obras Públicas y Arqueología Industrial.

La planificación turística en estos espacios debe ser muy cuidadosa con los impactos que se puedan derivar sobre el ambiente físico y los valores socioculturales del medio receptor, por lo que es importante realizar estudios sobre la demanda para poder integrarla en el territorio adecuadamente. 
El desarrollo turístico de las áreas serranas, surgido espontáneamente, ha dado lugar en algunas zonas a un naciente mercado inmobiliario y de alquiler de casas rurales, destinado a un nuevo turismo que demanda un recurso distinto con una estacionalidad menos marcada.

Sin embargo, la falta de control puede resultar peligroso, ya que se circunscribe a las exigencias de la demanda sin tener en cuenta la fragilidad de los recursos turísticos a explotar y el deterioro de los mismos y, por tanto, el propio atractivo del ambiente rural.

Esta problemática se refleja hoy día en algunas áreas de montaña españolas, como Gredos, escenarios de numerosos conflictos en los últimos años entre lo rural y lo urbano, con una clara resistencia de sus habitantes a la especulación destinada a convertir la Sierra en área de segunda residencia.

No hay que olvidar en este apartado, que el turismo rural o natural ha sido olvidado en comparación con los recursos del sol y playa en nuestra provincia en particular y en España en general, a pesar de que la demanda va adquiriendo un carácter masivo, superando la cifra de 4.000.000 de personas de 1983 (BOTE, 1984).

Tan sólo en el caso de los Parques Naturales andaluces declarados por ley: Cazorla, Segura y las Villas y Grazalema, acogieron entre Enero y Agosto de 1983 a 900.000 visitantes (MEDIO AMBIENTE, 1986), lo que supone una cifra de gran trascendencia si se tiene en cuenta que sólo se han hecho tímidos avances en el sector turístico en estos espacios protegidos.

Este fenómeno de nuevo turismo no ha escapado al interés de los estudiosos, de tal manera que con el objeto de diseñar una política idónea en este campo, el C.S.I.C. inició en 1983 un programa de investigación sobre Instrumentos de Ordenación, Gestión y Promoción del Turismo Rural en España.

Aunque en la mayoría de los países europeos existen desde hace años Agencias de Viaje especializadas en turismo ecológico, que exploran la demanda turística que huye el turismo de masas y busca el contacto con la naturaleza, con actividades que van desde la caza fotográfica hasta los itinerarios ecológicos, en España este enfoque del turismo es casi desconocido, aunque ya existe alguna empresa dedicada al mismo como Caminos \& Caballos, S.A., que se dedica a la organización de viajes a través de caminos rurales tradicionales, como los de la trashumancia entre Extremaudra y Avila (Gredos).

Asímismo, la utilización del patrimonio como equipamiento turístico preexistente, está yendo más allá de la dimensión histórico-artística convencional, explorándose aspectos singulares, como la arqueología industrial, las obras públicas, etc. 
Así, han aparecido diversos trabajos publicados en los últimos años sobre la recuperación de las cañadas reales de la Mesta, que constituyen más de 80.000 $\mathrm{Km}$. de caminos rurales de dominio público, de gran interés naturalístico y ecológico, que en multitud de sitios han sido ilegalmente privatizados o destruidos sin contemplaciones y que pueden tener una clara proyección turística.

La Sierra de Huelva posee una enorme riqueza de caminos rurales (BELTRAN, 1986) con una clara proyección turística, por discurrir generalmente por paisajes agrestes de gran belleza.

Existen vestigios o evidencias de algunos caminos históricos como la Prerromana Ruta de la Plata de Tartessos o las frecuentes calzadas romanas. Asimismo, son muy abundantes todavía las Cañadas de la Mesta y otras de trashumancia provincial, así como Caminos de rueda y de herradura y caminos rurales tradicionales (reales, de herradura, de carne).

Esta red de caminos poseen todavía unos valores indudables desde diversos puntos de vista (BELTRAN, 1986). Así presentan una utilidad socioeconómica en relación con los movimientos del ganado y con actividades agrícolas y forestales. También destacan por sus valores históricos, por existir caminos pertenecientes a todas las épocas, desde la ocupación de estas tierras por el hombre. Destacan también los valores ecológicos (hidrografía, flora, fauna, etc.) y estéticos (obras integradas en la naturaleza circundante), etc.

Además de lo anteriormente expuesto presentan dos potencialidades no exploradas hasta el momento, su proyección educativa y sus posibilidades turísticas. Así, las orientaciones diversificadoras de la oferta en el turismo actual, permitirían que en el futuro los valores ecológicos y paisajísticos de la sierra onubense, enmarcados en una orografía suave y transitable, pudieran ser explorados por un turismo que desarrollara sus actividades de forma peatonal y ecuestre a través de la amplia y atractiva red de caminos rurales tradicionales existentes, que se constituiría en la infraestructura viaria ideal.

La afición ecuestre tran arraigada en la provincia y los buenos productos que se obtienen a través de los programas de remonta en las tierras altas, permitirían la puesta en funcionamiento de una red de circuitos a caballo por los caminos serranos con una repercusión económica directa sobre la población.

\section{EL ANDEVALO: TURISMO CINEGETICO Y ECOLOGICO}

El Andévalo, la otra gran comarca onubense a caballo entre las zonas de campiña-litoral y la sierra, con carencias en cuanto a paisajes atractivos de carácter extremo, en comparación con playas y sierras, posee sin embargo una gran potencialidad desde tres puntos de vista: 
- Paisajes agropecuarios: las dehesas.

- Zonas de gran valor cinegético.

- Zonas de gran interés ecológico.

La existencia de grandes extensiones de dehesas en este área a pesar de las transformaciones sufridas en los últimos años, para la implantación de árboles de crecimiento rápido (eucaliptos) para la fabricación de pasta de papel, motivada por una negativa política forestal (JARAMILLO, 1986; CLAVERO, 1987), hacen que sea muy atractiva desde un punto de vista rural y agropecuario, con la singularidad de la dehesa como invento ecológico de integración del hombe y sus actividades con la naturaleza.

Así, siguiendo a FERNANDEZ-ALES (1987), la dehesa es una forma tradicional de explotar el bosque mediterráneo, en la que la mayor parte de la superficie está cubierta de un bosque aclarado de encinas y/o alcornoques con una densidad media de 50 árboles/Ha., de los que se obtiene leña para carbón, corcho y fundamentalmente bellotas para alimentar la ganadería porcina.

El sotobosque, cubierto de pasto, se explota con ganadería ovina y vacuna. También hay otros tipos de vegetación; cultivos de cereales y granos en las zonas cercanas al caserío, sobre las mejores tierras y matorral en la periferia en terrenos abruptos, en donde se caza, se alimentan las cabras y, a veces, se hace carbón.

Esta explotación mixta de unos recursos múltiples está basada en la propia regulación ecológica del sistema, para obtener una producción sostenida a largo plazo sin deterioro del medio.

Este uso tradicional de la tierra, tan integrado en el territorio y único en el mundo, corre un grave peligro de deterioro y desaparición, por el hundimiento de la economía ganadera asociado a la aparición de la peste porcina y, el progresivo abandono de las zonas rurales y de las labores de mantenimiento.

La recuperación de la dehesa pasa por una reestructuración del sector, con programas oficiales de apoyo a estas explotaciones y una adecuada promoción y prestigio de los productos de calidad que se obtienen de ella (chacinas, mieles, esencias, etc.).

El atractivo de la explotación en sí y su integración en el medio de las actividades tradicionales, de la belleza de los paisajes y de la degustación de una rica gastronomía con productos de altísima calidad, permite que se proyecte una red de casas de labor en distintos cortijos con explotación de dehesas, que se integren en circuitos turísticos, de manera que puedan ser visitados por grupos con interés en turismo rural y natural. 
Esta forma de turismo ya es practicada en otros países, como Francia, con gran éxito (Parques Naturales Regionales), ya que las explotaciones agropecuarias tienen una fuente subsidiaria de ingresos por su labor turística, que les permite sanear en gran medida su economía, no siendo necesario grandes ingresos en infraestructura de acogida.

Las extensiones de matorral mediterráneo que ocupan gran parte del andévalo, que constituyen etapas serales de degradación del bosque mediterráneo o situaciones climáticas, en el caso de algunos matorrales de mancha, han sido consideradas tradicionalmente como zonas marginales desprovistas de toda utilidad y sin rentabilidad económica.

Sin embargo, al margen de su gran valor ecológico, en función del papel que desempeñan en el equilibrio natural (MERINO, 1987), asociados a numerosos procesos como erosión, remoción de masa, hidrología, circulación de nutrientes, cobijo de fauna y flora, etc.; posee un uso potencial relacionado con nuevas formas de turismo, basado en el paisajismo, las reservas científicas y las explotaciones y reservas cinegéticas.

El dilema existente en la actualidad entre conservacionistas y cazadores, en relación con el perjuicio que causa la actividad cinegética sobre las comunidades animales silvestres, fundamentalmente sobre aquellas especies con mayor peligro de extinción (rapaces, mamíferos, etc.), se solventaría con una adecuada ordenación de las extensiones de matorral y bosque mediterráneo que aún existen en la provincia.

La racionalidad impuesta a la explotación permitiría la conservación de aquellas áreas de mayor valor ecológico, con la adjudicación de una figura legal de protección, como la de Paraje Natural; existiendo en el Andévalo dos zonas naturales idóneas para este fin: Sierra Pelada y La Pata del Caballo, que podrían ser integradas en programas de turismo ecológico o naturalístico.

Asímismo, la perfecta delimitación de zonas cinegéticas (de caza mayor y menor), donde se practicará la caza de forma ordenada y con absoluto respeto a la legislación vigente podría, mediante la adecuación de infraestructuras de acogida y la realización de una promoción idónea, generar la visita fuera de temporada alta de un turismo europeo de altísima calidad y elevada rentabilidad. 


\section{EL CATALOGO DE ESPACIOS PROTEGIDOS DE HUELVA COMO BASE PARA EL DESARROLLO DE UNA NUEVA} ALTERNATIVA TURISTICA

Con el desarrollo de la red de espacios protegidos de Huelva ya apuntada en el PEMF de reciente aprobación, se conseguiría una nueva alternativa turística para la provincia, dotándose aquellos espacios naturales más significativos y repressentativos de unos adecuados Centros de Recepción e Interpretación y una red de itinerarios naturalísticos de interés, con una infraestructura y equipamiento idóneos (CAMOYAN, 1984).

Se conseguiría de esta forma un entramado de espacios a lo largo de toda la provincia, a través de los cuales, se pudiesen explorar sus diversas riquezas: paisajes, geología, especies singulares, etc., y las distintas opciones de explotación tradicional de las mismas articulando la conservación del medio con la presencia del hombre y sus actividades.

Se buscarían las figuras legales de protección más adecuadas para cada zona (Parques Nacionales, Parajes Naturales, Reservas Integrales y Parques Naturales), pero permitiendo en todo momento el desarrollo de una verdadera oferta turística, como ya se ha conseguido en otros países (EE.UU., Reino Unido, etc.).

De esta forma se trata de evitar la repetición de experiencias de poco éxito, como la llevada a cabo hasta el momento en el Parque Nacional de Doñana, único espacio protegido onubense, que se ha centrado casi exclusivamente en programas educativos locales, normalmente subvencionados, que, como se ha visto, generan poca riqueza directa y que mueven un número muy bajo de personas al año (inferior a 200.000) uniéndose a ello una general insatisfacción por falta de programación en las visitas y de interés en lo visitado.

Doñana, en este sentido, es un claro ejemplo de política turística equivocada, ya que en aras de la conservación del Parque no se ha dado una adecuada promoción al mismo, ofreciéndose una imagen muy parcial de sus ecosistemas, cuando existe la posibilidad de reproducción artificial de los mismos en puntos de recepción de visitantes, lo que permitiría la acogida de un número muy superior de visitas, con un impacto mínimo, poniendo al servicio del sector turístico el medio natural, lo que redundaría en su propio beneficio.

La existencia de una amplia gama de ecosistemas en la provincia, ofrece la posibilidad de explorar rutas de naturaleza, que con inversiones no demasiado costosas en infraestructuras de acogida, abriría un campo turístico muy interesante, explorando hoy día enotros países de Europa y América con gran éxito de visitas. 
Así, la Red de Espacios Protegidos onubenses, propuesta por el PEMF, entre los cuales la AMA tiene en proyecto asignar status específico de protección a los más significativos, constituye un marco ideal de exploración de las nuevas posibilidades turísticas de la provincia, desde un punto de vista naturalístico y de apoyo y complemento al turismo convencional.

Esta red de espacios distribuidos por todo el ámbito provincial necesitaría una infraestructura mínima de acogida, los Centros de Recepción, Información e Interpretación, y varios sistemas alternativos de interpretación dependiendo del interés del visitante y su motivación, debiendo constar de los siguientes equipamientos:

- Sala de exposición e interpretación.

- Sala de proyecciones.

- Itinerarios peatonales naturales con reproducción de las condiciones silvestres.

- Itinerarios en profundidad con utilización de diversos medios (terrestres, acuáticos y aéreos).

Con ello se cubrirían las distintas posibilidades naturalísticas:

- Paisaje: Costa, Campiña, Marismas, Andévalo, Sierra.

- Ecosistemas: Litorales, Zonas Húmedas, Dehesas, Matorrales, Monte Mediterráneo, etc.

- Flora: Formaciones vegetales y especies singulares.

- Fauna: Acuáticas, Zancudas, Rapaces, Mamíferos, etc.

Se trataría de desarrollar el Catálogo de Espacios y Bienes Protegidos de la provincia creando:

- Información documental por extenso de todos los espacios.

- Desarrollo infraestructural de acogida de los más destacados (AMA) o adecuados para ello desde un punto de vista turístico.

Así, esta red podría ser explorada partiendo de ciertos puntos de interés, desde donde se organizarían rutas de diversa duración, sobreimpuestas a las ya existentes en la actualidad en la provincia o específicas de temas de naturaleza. 
En ellas se trataría de resaltar la relación cultura-naturaleza, ya que en una provincia colonizada desde tan antiguo no puede sustraerse la presencia del hombre en sus ecosistemas, ya que éste ha dado lugar a unos ecosistemas característicos, al margen de aquellos espacios con interés natural muy destacado (costa fundamentalmente).

Uno de los ejemplos más característicos de este proceso, como hemos visto, es la dehesa invento natural andaluz por excelencia, de la que existen en Huelva todavía grandes extensiones, aunque en grave peligro de deterioro y desaparición.

En ella se puede estudiar esta relación mediante:

- Análisis cultural y naturalístico de un régimen mixto de explotación de las fincas con dehesas, matorrales, cultivos, ganado, caza, etc.

- Uso racional de los recursos naturales con sistemas de explotación adaptados al medio.

- Necesidad de gestión e intervención humana para el mantenimiento de un ecosistema en el que conviven explotación y conservación.

- Fauna característica.

- Sistema de explotación ganadera: podas, aclareo, majadeo, montanera, ganadería brava, etc.

Este sistema tan valioso puede ser explorado en el Andévalo mediante la ubicación de casas de labor con cooperativas de explotación que sean visitables y donde se puedan degustar y admirar y contemplar los paisajes y sus biocenosis.

El mantenimiento y mejora de las grandes extensiones de matorral, con un fin mixto, dependiendo de la vocación del terreno, naturalística o cinegética, permitiría explorar un turismo europeo de alta calidad, respetuoso con el ambiente, en zonas andevaleñas y serranas.

Por último, una explotación turística integral, con una estructura de Parque Natural en la Sierra, posibilitaría el uso de un recurso turístico potencial el desarrollo sostenido como forma de explotación racional de un área de montaña, aprovechando también en este caso como hecho primordial la imbricación cultura-naturaleza y sus distintas manifestaciones (cultura, folklore, historia, gastronomía, etc.).

La Ley 15/1975, de 2 de Mayo, de Espacios Protegidos y la Ley 1/1970 de Caza, ofrecen la posibilidad de desarrollar figuras legales de protección diferentes, que se adecuarían a las características de los diferentes espacios en los que se desarrollarían programas de visita: 
- Ecosistemas costeros: Parajes Naturales.

- Zonas Húmedas relevantes: Reservas Integrales.

- Dehesas y matorrales: Parajes Naturales.

- Sierra: Parques Naturales.

- Zonas cinegéticas: Reservas de Caza.

Sobreimpuestas a estas figuras se podría utilizar en aquellos espacios más destacados, como ya ocurre en Doñana y Odiel, la categoría de Reserva de la Biosfera (MaB-UNESCO), para dar un mayor realce al programa en los círculos internacionales, teniendo en cuenta además las directrices internacionales, en las que predomina la orientación de la presencia del hombre y sus actividades en el medio natural y su potenciación y difusión por medio de la educación ambiental y el turismo (MaB, 1986).

La red básica de este programa quedaría formada por los siguientes espacios:

\section{LITORAL}

- Doñana: Parque Nacional.

- Asperillo: Paraje Natural.

- Laguna de las Madres: Reserva Integral.

- Marismas del Odiel: Paraje Natural y Reservas Integrales.

- Enebrales de Punta Umbría: Paraje Natural.

- Laguna del Portil: Reserva Integral.

- Flecha del Rompido y Marismas del Piedras: Paraje Natural.

- Marismas del Guadiana y Carreras: Paraje Natural.

\section{ANDEVALO}

- Pata del Caballo: Paraje Natural.

- Sierra Pelada: Paraje Natural.

- Dehesas de Paymogo: Paraje Natural.

- Dehesas de Santa Bárbara: Paraje Natural.

- Dehesas de las Capellanías: Paraje Natural.

- Terrenos cinegéticos por determinar: Reservas o Cotos Nacionales de Caza.

\section{SIERRA}

- Parque Natural constituido por distintas zonas de El Castaño, Hinojales, Bujo, Aroche, Encinasola y La Umbría-Puerto Moral, con unas 30 ó 40.000 Has.

- Alcornocales de Cala: Paraje Natural. 


\section{LA EXPOSICION DEL 92: UNA OPORTUNIDAD PARA HUELVA}

La gran inversión necesaria para la implementación del proyecto propuesto, encontraría un marco adecuado que la justificaría, en otra muy superior que se va a producir en Andalucía con motivo de la celebración de la Exposición Universal de Sevilla de 1992, en conmemoración del Descubrimiento de América.

El protagonismo de Huelva en el hecho colombino, los diecisiete millones de visitantes de todo el mundo que se esperan, la corta distancia a Sevilla y las envidiables condiciones naturales de la provincia de Huelva en comparación con aquélla, permitiría que se utilizara esta última como apoyo turístico en el que se explotaran sus riquezas ambientales, frente al carácter predominantemente urbano del atractivo de Sevilla.

España y, sobre todo Andalucía, va a tener la posibilidad de mostrarse al mundo como un escaparate culto (LOPEZ PALANCO, 1986), bien organizado con motivo de la Expo'92 y de las Olimpiadas de Barcelona, faltando en las previsiones actuales el desarrollo de un proyecto integrado de conservación y turismo, lo que constituye hoy día uno de los principales componentes de la cultura del hombre moderno. Desde este punto de vista, Huelva podría aportar al acontecimiento el desarrollo de una capacidad de acogida orientada en dos direcciones perfectamente compatibles, de un lado el turismo cultural ligado al desarrollo del Plan Especial para la Ordenación y Protección de los terrenos de la Rábida, con una proyección histórico-artística de relevancia (CONSEJERIA DE POLITICA TERRITORIAL, 1985) y un turismo de naturaleza, que apoyándose en el desarrollo de infraestructuras convencionales explore los espacios naturales de la provincia, utilizando unos equipamientos idóneos para este fin, que habría que implementar en el curso de los próximos cinco años.

\section{CONCLUSIONES}

- Posibilidad y necesidad de coexistencia de conservación y turismo.

- Necesidad de zonas conservadas para el esparcimiento y ocupación del tiempo de ocio en la sociedad actual.

- Proceso histórico de desarrollo turístico exclusivamente costero fracasado.

- Necesidad de ampliación de la oferta a toda la provincia utilizando como atractivo recursos diversos, en toda época para combatir la estacionalidad. 
- Necesidad de apoyo institucional en la diversificación territorial, búsqueda de nuevos recursos, captación de servicios hoteleros, mejora de infraestructura y equipamiento, asesoramiento, coordinación y promoción.

- Planificación turística basada en estudio serios de ordenación con participación de especialistas de diferentes campos y distintas administraciones.

- Utilización del turismo de naturaleza como complemento del convencional.

- Uso Público y promoción deficientes en los espacios protegidos declarados en la actualidad en Huelva: Doñana y Marismas del Odiel.

- Potencialidad no despreciable del turismo de naturaleza con una adecuada planificación y promoción.

- Medio conservado adyacente a los núcleos turísticos litorales como punto esencial de su atracción para un turismo de calidad.

- Necesidad de infraestructura y equipamiento integrados en el entorno natural.

- Utilización de nuevos medios de acercamiento al recurso turístico.

- La filosofía de Parque Natural se considera idónea para la utilización turística de la sierra onubense, llevando a cabo programas de turismo rural.

- El Andévalo puede ser la base de un turismo mixto que explore las actividades agropecuarias, naturaleza y explotación cinegética.

- El Catálogo de Espacios Protegidos de Huelva del PEMF se considera como base para el desarrollo de estas nuevas alternativas turísticas.

- El protagonismo de Huelva en el hecho colombino justificaría las inversiones a realizar a corto plazo en un supuesto program piloto de desarrollo de nuevas formas de turismo, utilizando como principal recurso la naturaleza, su conservación y la integración de las actividades humanas en la misma. 


\section{BIBLIOGRAFIA}

A.M.A. (1985): Informe sobre la visito realizada a los Parques Naturales regionales franceses, Documento inédito, AMA, Sevilla.

AZCARATE, T. (1986): "Política de Parques Naturales en Andalucía". Actas del 1. " Congreso Nacional de Parques Naturales: 9-11, Sevilla.

BARRANCO, J. (1987): "La política turística para la provincia de Huelva". Primer Congreso de Empresarios, F.O.E., Matalascañas.

BELTRAN, V. (1986): Los caminos rurales en la Sierra de Huelva, Documento inédito.

BOTE, V. (1984): Plan de acción sobre conservación y desarrollo de los recursos turísticos de la comarca de La Vera (Caceres).

CAMOYAN, A. (1984): “Turismo y Uso Público en zonas húmedas andaluzas”. En: Las Zonas Húmedas en Andalucía, 219-225, MOPU.

CAPUTI, N. y LENANTON, R. (1977): A. Survey of the recreational usage of south coastal estuaries of western Australia, Report n. ${ }^{\circ} 27$, Department of fisheries and wildlife western Australia, Perth.

CLAVERO, J. (1987): "Por una alternativa a la política forestal en Andalucía", Encuentro por la defensa del bosque y matorral mediterráneo, Huelva.

COMISION INTERMINISTERIAL DE TURISMO (1963): Proyecto de promoción turística de la costa de Huelva.

CONSEJERIA DE POLITICA TERRITORIAL (1985): Exposición avance Plan Especial de La Rábida, Huelva.

CONSEJERIA DE TURISMO (1985): Programas de selección de comarca para actuación en turismo rural, Sevilla.

COPEIRO, E. (1978): "Los ritmos naturales de nuestras playas", Revista de Obras Públicas, Mayo 1978, 361-368.

COPEIRO, E. (1982): "Playas y obras costeras en España", Revista de Obras Públicas, Agosto 1982, 531547.

COPEIRO, E. (1985): Actuación urbanística en Nueva Umbría: Estudio de condicionantes ambientales, Documento inédito.

DIAZ DEL OLMO, F. y MOLINA, F. (1985): "Parques Naturales andaluces. Una estrategia de conservación y desarrollo en regiones deprimidas”, Revista de estudios andaluces, $\mathrm{n} .{ }^{\circ} 4$.

EPYPSA (1986): Plan Especial del Medio Físico y Catálogo de Espacios y Bienes Protegidos de la Provincia de Huelva, Consejería Obras Públicas, Sevilla.

FEDERATION DE PARCS NATURELS DE FRANCE (1982): Les Parcs Naturels Regionaux: Bilan et perspectives.

FERNANDEZ ALES, Rocío (1987): "Las dehesas, una forma tradicional de explotación del matorral mediterráneo", Encuentros por la defensa del bosque y el matorral mediterráneo.

FERNANDEZ-PALACIOS, J.M.; FIGUEROA, M.E. y RUBIO, J.C. (1985): "Flecha litoral del Rompido y Marismas del Río Piedras. Field Trip to Spain. British Ecological Society", Publicaciones del Departamento de Ecologia, Sevilla. 
FIGUEROA, M.E. y RUBIO, J.C. (1980): "Unidades Ambientales del litoral onubense. Primer curso premio Príncipe de Asturias", Publicaciones del Departamento de Ecología, Sevilla.

GARAY, J. (1985): "La gestión de los recursos en los Espacios Naturales Protegidos: El Parque Natural de Cazorla, Segura y las Villas", Actas del primer Congreso Nacional de Parques Naturales, 16-28, Sevilla.

GARCIA NOVO, F. (1980): “Descripción ecológica del Parque Nacional de Doñana. Primer curso Premio Príncipe de Asturias”, Publicaciones del Departamento de Ecología, Sevilla.

GARCIA NOVO, F. (1981): "Efectos ecológicos del equipamiento turístico", Coloquio hispano-francés sobre Espacios Litorales, 159-168.

SERVICIOS DE PUBLICACIONES AGRARIAS, Madrid.

ICONA (1984): Plan Rector de Uso y Gestión del Parque Nacional de Doñana.

JARAMILLO, A. (1986): "El otoño del bosque mediterráneo", Revista MOPU, Febrero 86, 52-57.

LABORATORIO DE PLANIFICACION TURISTICA (1986): Andalucía 2000. Nuevas alternativas turisticas.

LAGUNAS DEL PORTIL, S.A. (1973): El Portil Center of national touristic Interest, Seix Barral, Barcelona.

LOPEZ PALANCO, R. (1987): "De la realidad del '29 a la ilusión del ‘92”. Conferencias, Club Antares, Sevilla, Vivir Sevilla, n. ${ }^{\circ} 6,46-54$.

$\mathrm{MaB}$ (1987): Las reservas de la Biosfera en el Mediteráneo, Atélier Florac, Francia.

MARCHENA, M. (1986): El turismo en Andalucia (Tesis Doctoral), Universidad de Sevilla.

MENANTEAU, L. y VICENTE, A. (1983): "De la ría de Huelva a la desembocadura del Guadalquivir: Unidades de paisaje y usos turísticos”. En: Turismo y Desarrollo Regional en Andalucía, Instituto de Desarrollo Regional, n. ${ }^{\circ} 24,321-340$, Universidad de Sevilla.

OJEDA, J.F. (1986): “Actividades humanas en el territorio". En: Huelva y su provincia, Ediciones Tartessos, Huelva.

RICHEZ, G. (1986): Parcs Nationaux et Tourisme en Europe (Thése de Doctorat). Universite d'AixMarseille.

RUBIO, J.C. (1980): "Vertebrados de Doñana. 1. ${ }^{\text {er }}$ Curso Premio Príncipe de Asturias", Publicaciones Departamento de Ecología, Sevilla.

RUBIO, J.C. (1985): Ecología de las Marismas del Odiel (Tesis DoctoraI), Universidad de Sevilla.

RUBIO, J.C.; FERNANDEZ-PALACIOS, J.M. y FIGUEROA, M.E. (1985): "Importancia ecológica de la flecha litoral del Rompido (Nueva Umbría)", Publicaciones del Departamento de Ecología. Sevilla.

RUBIO, J.C. (1986): Plan Rector de Uso y Gestión del Paraje Natural de las Marismas del Odiel, A.M.A.

ZAMORA, F. y NICOLAS, J.M. (1985): "Motivaciones y perfil medio de los visitantes del Parque Regional de la cuenca alta del Manzanares", Actas del I Congreso Nacional de Parques Naturales, 152 156, Sevilla. 